\title{
Avoiding the pitfalls of growth
}

\author{
Should we insist that "a little chaos is a good thing?" \\ Elton N. Kaufmann \\ MRS President
}

L ast February, I received a letter from the long-time executive secretary of the Society, Ernest M. Hawk of the Pennsylvania State University. Ernie's association with us dates back to the Society's inception. He was the only focus of activity that could legitimately be called a headquarters operation of sorts. While the role of his office was crucial, a great deal of the day-to-day business of the Society (which was nearly exclusively planning the Boston meeting) was dispersed among the various Officers and program and symposium chairs. In those days procedural guidelines were nonexistent. A healthy dose of common sense, technical judgment, and many telephone consultations sufficed. Those of us who enjoyed that free hand and suffered that lack of definitive guidance are most sensitive to the changes that are overtaking our Society as it grows. Thus the following excerpt from Ernie Hawk's letter struck a resonant chord. He wrote:

"Those of us involved in the organization through the early struggling years cannot help but be awed by the growth and vitality it has attained. The impressive signs are all around-the quality of and interest in its technical programming, the increasing number and geographical spread of technical meetings (we've come a long way from that one Boston meeting a year), the flourishing publications business, the exhibition feature, and more.

"Then, too, we have competent professional services to support and facilitate this energetic enterprise. I, especially, can appreciate the importance of the work done by the headquarters support staff which MRS needed so badly, and I rejoice that it is now in place and functioning so effectively.

"Yet it is these very accomplishments which give me pause for reflection. I am concerned, in the first instance, about growth that is too rapid and uncontrolled, that may in the long run work to the detriment of the body.

Perhaps we should have a strategy or technique for doing periodic growth impact assessment to provide guidance in this area.

"Similarly we must find a way to ensure that an enlarged professional staff does not choke off the dynamic voluntarism that has, in my opinion, been the secret of MRS's rapid rise as a respected technical society. So we also need a strategy to keep voluntarism and professionalism in wholesomely productive partnership."

These concerns are not unique to MRS. As anyone knows who has observed the growth of organizations in many other spheres, there is an inexorable sequence of entirely predictable stages as the evolution from small and entrepreneurial to large and bureaucratic progresses. ${ }^{1}$ The question is how and at what price does MRS avoid the pitfalls of growth?

As the activities of MRS expand beyond that manageable by a small cadre of volunteers, we are indeed seeing an ever increasing tendency to transfer responsibility for and implementation of tasks to our professional staff. Naturally in this way, we can be assured of expert support and of the continuity from year to year that volunteers often do not provide. We are in fact experiencing a decided increase in efficiency and the elimination of many of the cracks through which things frequently fell. Each decision we make as we add professional services in support of MRS, whether through outside contract or at our headquarters, is guided by our sincere desire to replace a degree of chaos with a degree of order. An eminently reasonable goal! To some extent, this addresses the first qualm of Ernie Hawk's letter So what's the problem? There is no obvious one now. But, as Ernie Hawk warns, a blind continuation of the present trend may be self-defeating. As our size increases further, the only scenario easily envisioned is one engendering a proliferation of guidelines, forms, rules, and procedures. Committees and subcommittees will act and react more slowly in the face of decreasing effectiveness over ever more complex issues. In this environment, the seeds of initial MRS success-individual initiative, highly motivated counterstream swimmers, freedom to innovate, quick realization in concrete terms of the investment of time and energy-would be unlikely survivors.

The MRS is not about to suffer this fate soon. And although the pundits of organizational culture insist that it is eventually unavoidable, we can ask what is to be done today to delay it. Is it possible to preserve the essence of that initial spark while maintaining the skeleton of a large, healthy, growing organization? Can one combine the extremism of youth with the prudence of age? As iconoclastic as it sounds, should we insist that "a little chaos is a good thing?" Yes, with one rather significant qualification. To effect the preservation of that rare commodity, the influential volunteer in the flexible organization, a clear sense of the need to avoid construction of the stifling bureaucracy must be maintained at the front of everyone's consciousness - the Officers, staff, and members, alike.

Of course, this is easier said than done. There is evidence, however, that for now, some have accepted this challenge. Most Society activities are too young to be used as a point of reference, but meeting programming has been around for quite a while. In this area, on a few occasions, proposals have arisen to create official topical committees within MRS to husband frequently repeating symposia at our meetings. Ad hoc groups do already exist, but the official posture of our Program Committee has so far been to avoid any mechanism that might replace the yearly revamping of our programs with potentially self-perpetuating entities. This exemplifies the kind of healthy skepticism of overstructuring that will stand us in good stead for the future.

Many feel that to stress the above long-range concern in these pages, at a time when so many crucial short-term issues require discussion and debate, indicates inverted priorities. I hope that is true, but just in case it's not, let me ask all members of MRS to act as self-appointed keepers of the elusive spark that has served us so well until now. Give the Society leadership and your fellow members your views both directly and through the pages of the BULLETIN. The test will come 10 or 15 years hence when this editorial is unearthed from Society archives and compared with the then existent MRS. M/R

1 See for example. The Management Challenge, Rohrer, Hibler \& Replogle, Inc (The New American Library. New York, 1981/ Chapter 8, p. $126 f f$. 